skiagram the abrupt line of demarcation between the dilated and the non-dilated portions of the ureter is demonstrated. The former obviously extends to, and is limited by, the site of the kink, below which the ureter is of normal size.

It may be assumed that with the removal of the obstruction the ureter and pelvis will shrink down to their original sizes, though it will possibly be a difficult matter to get rid of the infection. During the last three months, however, treatment with urinary antiseptics and an autogenous vaccine have definitely improved the condition, the pyuria and pain having almost disappeared.

I am indebted to Sir Watson Cheyne for permission to publish the notes of his case, and for his remarks regarding the operation; also to Dr.R. Knox, honorary radiographer to King's College Hospital, for permis. sion to publish his skiagrams.

Remarks on the Operation by Sir W. WATSON CHEYNE.

When the question of operation in this case was placed before me the main point which I considered was whether the diverticulum should be approached by an extra- or intra-peritoneal operation. These cases have usually been dealt with extraperitoneally, but this seemed to me to be a method which was not free from considerable risk. The wound is a deep one, and it is not easy to deal thoroughly with the stump after removal of the cyst, and especially to prevent infection of the cellular tissue from the septic condition of the mucous membrane at the divided part. Hence in the extraperitoneal method there must be considerable risk of deep-seated suppuration and possibly of urinary fistula, which might be very difficult to close. Indeed, such conditions seem to be not uncommon after extraperitoneal operations. On the other hand, if dealt with from inside the peritoneal cavity the neck of the diverticulum is easily within reach, and if any septic fluid escapes it can be received on packing, or if any reaches the peritoneum it will deal with it more readily and perfectly than the cellular tissues.

The operation was quite simple and easy. The sac having been made prominent by pressure over the bladder, a curved incision was made through the peritoneum on the inner side of the neck (so that the stitches should not afterwards lie over the stump); the sac was isolated, its neck clamped just beyond the point of ligature so as to prevent escape of its contents, the neck cleared, ligatured with catgut as close to the mucous membrane of the bladder as possible, and cut across just beyond the ligature; the sac was then removed and the cut surface of the stump cauterised with undiluted carbolic acid. The stump was then pushed inwards while the muscular wall of the bladder was stitched over it with catgut; the incision in the peritoneum was then closed. In fact, the neck of the sac was treated practically in the same manner as the stump of an appendix.

After the operation the patient was placed in the high Fowler position so that the intestines should press the peritoneum over the bladder, and so as to prevent the formation of a space containing blood clot.

London, $\mathrm{W}$.

Scientrific Research : New Beit Fellows.The trustees of the Beit Fellowships for Scientific Research have elected to fellowships the following:-Mr. William Burgess Haines, B Sc., Mr. Caristopher K. Ingold, B.Sc., and Mr. Henry N. Walsh.

\section{TREATMENT OF WOUNDED SOLDIERS BY THE THERMAL WATERS OF AIX-LES-BAINS, SAVOY.}

\author{
By DOCTOR LEON BLANC.
}

THERMAL waters have at all times been used in the treatment of wounds inflicted by military weapons. One can even go so far as to say that the first persons to start the use of thermal waters were surgeons, and that these waters gained their original reputation by their effects on wounds inflicted by the arquebuse (hence the name of "arquebusade" which has been adopted ever since). All thermal waters have a beneficial and curative effect in the treatment of war wounds, both as regards their immediate and remote effects. The benefits obtained from thermal waters are dependent upon their chemical composition, temperature, volume, and radio-activity, as well as on the various ways in which they are used.

At Aix-les-Bains the good results which are being obtained are mainly due to the chemical properties of the water, together with its natural characteristics of warmth, radio-activity, volume, and high degree of pressure. The Aix waters are sulphuretted, the two springs of "alum" and sulphur show 3-4 degrees on the Dupasquin sulphydrometer. Their output is 1,000,000 gallons in 24 hours at a temperature of $115^{\circ} \mathrm{F}$. The waters are applied by means of tubs, tanks, shower baths, massage (general and local), and vapour baths (general and local). The latter are known as Berthollet vapour baths. The massage is undertaken by a staff of male and female experts.

The happy results obtained at Aix-les-Bains are attributable to the coopperation of the following factors: 1. The Zander Institute, where all mechanico-therapeutic and electro-therapeutic appliances may be found. 2. Potable waters with a low mineralisation for the purpose of flushing the internal organs. The springs supplying these waters are the Saint-Simon, les deux Reines, and Massonat. 3. The highly sulphuretted waters of Challes and Marlioz (near Aix) are of value in the treatment of bronchial affections. 4. Lastly, the situation of Aix amongst magnificent Alpine surroundings, its pure air and mild climate, and the places of high altitude in the neighbourhood constitute a health resort with which few others can compare.

The various therapeutic elements explain and justify the reputation which Aix has always enjoyed. Already in 1870, although the Zander Institute had not yet been built, the Aix waters were employed with considerable success, and the Medical Society of Saroy had summed up as follows the cases where such waters should or should not be used: 1. The waters cleanse wounds and hasten the healing process. 2. They relieve pain. 3. They counteract the development of paralysis by stimulating nervous energy and by raising the tone and nutrition of the muscles. 4. They relieve muscular contracture and restore the free movement of tendons and articular surfaces in pseudo-arthroses and pseudo-ankyloses. 5. They facilitate the resolution of traumatic engorgement. 6. They promote the restoration of sensibility in certain cases of paræsthesia. 7. They reduce connective-tissue hypertrophy. 8. They disclose and favour the elimination of splinters and other foreign bodies which the surgeon may have overlooked. 9. Lastly, they have always 
proved of great value in the treatment of all rheumatic and gouty conditions, and their associates neuritis, sciatica, phlebitis, \&c. In most of these diseases the waters must necessarily be used in conjunction with massage, mechanico-therapy, and electricity. The successful treatment of wounded soldiers at Aix-les-Bains in 1870 is fully recorded in the publications of Dr. Brachet, Dr. Davat, Dr. Guilland, and Dr. Legrand.

It may be asked whether the good results obtained are not chiefly due to the therapeutic appliances employed at the thermal establishment. This is not so, as many patients have undergone similar treatment in various hospitals before coming to Aix without obtaining complete relief. Since the outbreak of the present war numerous wounded officers and men have been sent here. Nearly 400 selected cases are now under treatment.

It would not be possible, for obvious reasons, to attempt at the present time to summarise the results obtained; but it may serve a useful purpose to indicate the classes of cases in which thermal treatment appears to be giving the most encouraging results.

The value of the treatment in all gouty and rheumatic affections is well known and does not need further notice here.

Fractures. - Thermal treatment is not called for in simple fractures, but is of much benefit whenever they are followed by pain, stiffness, or contracture. In severer cases accompanied by limitation of movement from deformity or excessive callus formation the treatment is of little benefit. In cases of pseudo-arthrosis the waters are also powerless. But exceptions are met with where there is a strong gouty or rheumatic factor present. In the latter, results have been obtained which exceeded all expectations. Dr. Brachet has published an account of some remarkable cases of this nature in rheumatic patients. Complicated fractures are those which derive the greatest benefit from the treatment. Such are fractures accompanied by tearing of the muscles and effusions of blood in the deeper tissues, comminuted fractures, and fractures accompanied by suppuration and necrosis of bones.

Sprains.-All sprains, whether recent or not, can be cured with the help of mechanico-therapy and massage. It must, however, be borne in mind that a sprain may cause synovitis, in which case the waters would be powerless to effect a cure.

Dislocations.-In the majority of cases, after reduction, recovery takes place unaided; but if pain persists, with articular or muscular stiffness, thermal treatment with mechanico-therapy and massage is of value, particularly in gouty or rheumatic cases.

Ankylosis.-Thermal treatment, with massage and mechanico-therapy, applied to these cases is the most successful of all. The results are particularly remarkable in cases of slight ankylosis. In ankylosis of the knee, if the knee-cap is mobile, recovery is almost certain. But in complete ankylosis, whether bony or fibrous, the results are generally negative. But eren here perseverance is sometimes rewarded. I have seen cases of complete ankylosis yield to two or three courses of treatment. It is worth trying thermal treatment in ankylosis following suppurating arthritis, but the patient should not be sent to Aix until two or three months after suppuration has completely ceased.

Arthritis.-The same applies to this malady as has been said with reference to ankylosis-usually

\footnotetext{
1 See Rochard: Mineral Waters and their Use in Surgical Cases.
}

arthritis is of rheumatic or gouty origin, and here Berthollet vapour baths and shower baths are to be recommended. The patient should never be moved during the critical period. Frequently arthritis and ankylosis are attended by muscular atrophy, and here, again, massage and mechanico-therapy, with electric treatment, should be added to the thermal treatment.

Gunshot wounds.-The indications for thermal treatment in accidents resulting from this cause are the same as those described above. Gunshot wounds of internal organs, it need hardly be said, are not amenable to this form of treatment.

Phlebitis.-In cases of rheumatic or gouty origin or resulting from traumatism a rapid cure may be obtained by the cautious use of baths, underwater douches, and massage under certain conditions.

In most of the cases above mentioned a cure of three to four weeks is generally insufficient. The slower the cure the better the results. Satisfactory results are rarely obtained under 40 to 60 days.

The following cases, treated at the Auxiliary Hospital (Hospice Thermal) by Dr. Chaband and myself, may be quoted to illustrate the above remarks.

CASE 1.-Lieutenant - Nov. 28th, 1914, suffering from the results of having been crushed; very painful phlebitis with thrombosis; inability to walk. Admitted Jan. 23rd; calf of the leg, elbow, and foot all much emaciated; venous swellings very painful ; walking nearly impossible. Treatment: Baths with underwater douches and dry massage until Feb. 25th. Left the hospital completely cured.

CASE 2 -Private —, wounded Sept. 22nd, entered the hospital Oct. 2nd almost in a dying condition; violent secondary hæmorrhage ; fracture of the bones of the pelvis by a bullet; large intrapelvic abscess; extraction of many bone fragments at several operations ; very painful phlebitis of the internal saphena of the left leg; swelling of the limb. Continued surgical treatment until April 18th. The wounds having healed, he was given baths with underwater douches till May 16th. Swelling and pain disappeared, the limb resumed its normal size, and the patient was able to walk without crutches.

CASE 3.-Captain -. Rheumatism and sciatica, with lumbago of left side, after three weeks at the front. Sciatica treated elsewhere for one month. Entered the hospital on Dec. 2nd, 1914; very painful sciatica of left side, with lumbago and neurosis of the right brachial plexus. Treatment: Underwater douches, with vapour baths, massage, and electricity for three weeks ; went away much better. Wrote a month later that he was completely cured and able to rejoin his regiment at the front.

CASE 4. - Sergeant __. Gunshot wound of anterior and upper portion of the forearm and upper arm (left side); severe pain in lower part of brachial plexus with paralysis of the extensors. After a month's rest in an ambulance, came to Aix on Oct. 2nd, 1914. Much improved after 16 local douches and 16 vapour baths. Pain entirely lost and partial recovery of muscular power. Wrote a month later that he was completely cured and able to return to the front.

CASE 5. - Private - -.. Injury to left thigh on Sept. 7th, 1914, through the bursting of a shell; considerable laceration of muscles. Admitted Sept. 17th. Wound healed after 40 days; still much pain with muscular rigidity and contracture; walking impossible. Complete recovery eventually obtained by douches, massage, and shower baths.

CASE 6.-Private —-, wounded Sept. 7th, 1914, admitted Sept. 10th, with large shell wound in the right thigh on the outer side, with considerable laceration of muscles. Three months under surgical treatment. The resulting fixation of hip-and knee-joints with contracture yielded almost entirely to douches and massage in 35 days. The patient was discharged fit for light duty.

CASE 7.-Private —, wounded Sept. 3rd, entered hospital on the 26th; bullet wound of right shoulder, traversing the humerus; healing rapid, followed by very painful scapular-humeral "arthritis," with partial ankylosis. Complete cure after three weeks of thermal treatment. 
CASE 8.-Private —, wounded on Sept. 27th ; bullet entered at the level of the left anterior superior iliac spine; point of exit on same side posteriorly; fracture of bones; very severe secondary hæmorrhage; extraction of numerous splinters on several occasions. Phlebitis of the right internal saphena, with considerable œdema of the limb. Three months under surgical treatment. Recovery from pain and œdema of leg much aided by douches and light dry massage.

CASE 9.-Lieutenant - injured on Sept. 13th, 1914. Dislocation of knee by falling into a hole, with consecutive painful arthritis. Admitted on Oct. 4th with persistent arthritis and considerable swelling. Acute pain; powerlessness of limb; paralysis of muscles of leg and foot; loss of knee-jerks; atrophy of thigh and leg (3 centimetres). Treatment consisted of douche massage, shower baths, dry massage, and electricity. On Dec. 3rd the patient was able to walk several kilometres and able to return to active duty.

CASE 10.-Sublieutenant -_. Railway accident on August $23 \mathrm{rd}$. Dislocation of knee, with very painful arthritis. Admitted to thermal hospital on Oct. 17th with painful arthritis of $\mathrm{knee}$, paralysis of the muscles of the left foot, and almost complete loss of sensation; diminished knee-jerk ; muscular atrophy of thigh (4 centimetres); walking impossible. Considerably improved after 47 days of thermal treatment. Three weeks later was able to rejoin his regiment on active service.

CASE 11. Colonel -__, wounded by bullet on August 26th in left loin (posteriorly), traversing left psoas muscle, producing considerable hæmatoma and arterio-venous aneurysm. Fracture of vertebral column at fifth lumbar vertebra (as seen by radiography); bullet lodged in right side of pelvis out of reach. Severe pain in sciatic and crural nerves of same side. Arrived at Aix three months after injury complaining of intense sciatic pains and inability to walk more than a very short distance. Followed thermal cure for one month and was able on leaving to walk 4 kilometres with ease; three weeks later was able to do 17 without pain, and wrote that he was able to return to the front.

Thermal treatment at Aix-les-Bains is given free to wounded soldiers of all ranks.

\section{SPIROCHÆTAL ULCERATION OF THE TONSILS IN SOLDIERS.}

BY WYATT WINGRAVE, M.D. DURH., M.R.C.S.' PATHOLOGIST, CENTRAL LONDON THROAT AND EAR HOSPITAL.

DURING the last few months I have received for diagnosis a striking succession of cases with deep ulceration of the tonsils in soldiers, both officers and men. They occurred, for the most part, in Territorials who were taken straight from civil life and sedentary occupations and put through a trying rapid training. Many of them were referred by their medical officers, some with a suspicion of syphilis, but it may at once be said that although the Wassermann test was applied in several of them the results were negative with one exception -an old soldier who had rejoined from the Reserve and had been invalided.

The affection is closely allied to, if not identical with, what is usually called "Vincent's angina," and is characterised by three prominent features(1) a deeply excavated and sloughing ulcer on one tonsil; (2) offensively foetid breath; and (3) the presence of spirochætes and fusiform bodies in great numbers. It may be arbitrarily divided into two groups-(1) acute, lasting from four to seven days; and (2) subacute, a more persistent type which lasts from two to three weeks.

The ulceration, which is always unilateral, generally begins as a sharply circumscribed raised white to grey patch, simulating a diphtheroid membrane.
It is, however, readily detached and not tough. The surrounding tonsil and mucous membrane are not much swollen, but may be red and slightly cdematous. There is usually no pain, and beyond a feeling of "seediness" the constitutional symptoms are not grave. Temperature rarely exceeds $101^{\circ} \mathrm{F}$., and the intense pain on swallowing so characteristic of acute peritonsillitis, or quinsy, is absent. In a few days the slough is either spontaneously detached or can be removed "en morceaux" with a swab, leaving a deep rough crateriform ulcer, which readily bleeds and is soon re-covered by more slough. The foetor is now unmistakeable and intense, closely resembling rotten fish. One striking feature is the sharply restricted area of the ulceration, for it rarely attacks both sides and never extends across the middle line. Sloughing slowly diminishes, and healing is complete in a few days, but if untreated it may persist for several weeks.

Diagnosis.-There need be no difficulty in the diagnosis, even in the early stage. When deeply ulcerated it has a most unpleasant and doubt. ful appearance. This is somewhat important, as Vincent's angina may occur in a syphilitic patient. In the event of a suspicious history Wassermann's test should be made, but this is hardly called for as a routine practice, since a swab examination will at once reveal the nature of the lesion.

Microscopical examination can be quickly done and is absolutely necessary. Collect an adequate quantity of the slough on a moistened "swab"; smear it on a clean slide; place another one over it; press them together firmly and separate by "sliding." This will make two thin films. Do not pass through a flame, but allow each one to dry in a warm place by radiant heat.

Negative staining should now be effected by pouring over the film a 5 per cent. solution of collargol in distilled water. Pour off quickly, then stand upright to drain, and dry in warm air. On no account must it be heated, or else fissures will appear in the film, which might be mistaken for spirochætes.

Positive staining is best done by the usual Gram method, but omitting thealcohol bath (anilin-gentian violet and iodine). By this means the spirochætes are adequately stained, while other features are overstained.

Films may also be examined "wet" without staining either by "dark-ground" illumination or by special adjustment of condenser and diaphragm. This is, however, far more difficult and less reliable than negative staining. Indian ink is not recom. mended, and is entirely superseded by silver colloid.

The slide is now examined with a 1/12-inch immersion lens, but a good "dry" 1/8-inch may sometimes prove strong enough. In the negative film spirochæotes and fusiform bodies appear brilliantly illuminated on a copper-coloured ground. The Spirochcta fotida, or Vincent's spirochæte, appears as a coarse undulating thread from 10 to 20 microns in length. It is not really spiral like Spirocheta pallida, but may show all variations from a slightly undulating filament bent, looped, or twisted, to a perfect spirochæte, either separate or in tangled groups or bundles, in striking contrast with the fine, closely coiled Spirochceta pallida. Vincent's spirochæte is really more like an eel or a whip-lash, while Spirochata pallida is like a coiled spring or corkscrew. 